OPEN ACCESS

Edited by:

Anne Laprie,

Institut Universitaire du Cancer de

Toulouse Oncopole, France

Reviewed by:

Eric Chi-ching Ko,

Cornell University, United States

Fady Geara,

American University of Beirut Medical

Center, Lebanon

${ }^{*}$ Correspondence:

Jack M. Qian

Jack_Qian@dfci.harvard.edu

Specialty section:

This article was submitted to

Radiation Oncology,

a section of the journal

Frontiers in Oncology

Received: 21 September 2020

Accepted: 16 December 2020

Published: 03 February 2021

Citation:

Qian JM and Schoenfeld JD (2021)

Radiotherapy and Immunotherapy for

Head and Neck Cancer: Current

Evidence and Challenges.

Front. Oncol. 10:608772.

doi: 10.3389/fonc.2020.608772

\section{Radiotherapy and Immunotherapy for Head and Neck Cancer: Current Evidence and Challenges}

\author{
Jack M. Qian ${ }^{1,2 *}$ and Jonathan D. Schoenfeld ${ }^{1}$ \\ 1 Department of Radiation Oncology, Dana-Farber/Brigham and Women's Cancer Center, Harvard Medical School, Boston, \\ MA, United States, ${ }^{2}$ Harvard Radiation Oncology Program, Massachusetts General Hospital/Brigham and Women's \\ Hospital/Dana-Farber Cancer Institute, Boston, MA, United States
}

Immune checkpoint inhibitors (ICl) have revolutionized cancer treatment over the past decade. However, although the immune landscape suggests a strong rationale for the use of these agents in patients with head and neck squamous cell carcinoma, the available clinical evidence indicates that most patients currently do not respond to $\mathrm{ICl}$ monotherapy. Radiotherapy is a primary treatment modality for many patients with locally advanced head and neck cancer. While ionizing radiation traditionally has been thought to act in a purely cytotoxic fashion, a growing body of preclinical studies have demonstrated additional profound immunomodulatory effects. Consequently, there has been a surge of interest in the potential synergy between radiotherapy and immunotherapy, both the potential for radiotherapy to augment the systemic anti-tumor immune response and the potential for immunotherapy to improve in-field tumor response to radiation. In this review, we summarize the current preclinical and clinical evidence for radioimmunotherapy, with a particular focus on studies directly relevant to head and neck squamous cell carcinoma, as well as existing challenges and future directions for this emerging field.

Keywords: anti-PD-1, immunotherapy, radiation therapy, head and neck cancer, anti-PD-L1

\section{INTRODUCTION}

Head and neck cancers comprise a significant portion of the global cancer burden; when aggregating subsites, they are the $8^{\text {th }}$ most common cancer worldwide by both incidence and mortality (1). Although the vast majority of head and neck cancers are squamous cell carcinomas (HNSCC) and have traditionally been associated with tobacco and alcohol use, HPV-associated oropharyngeal squamous cell carcinoma (SCC) has emerged as a new disease entity with markedly different biological behavior (2).

Ever since the foundational work of Henri Coutard, who was the first to use X-rays to treat laryngeal cancer almost 100 years ago (3), radiation therapy has played a key role in the treatment of HNSCC. Radiation continues to be used extensively both in the curative as well as palliative setting, although the distinction between the two is now sometimes blurred with growing recognition of the oligometastatic state, where patients with limited numbers of metastases can achieve prolonged survival, or even cure $(4,5)$. Technological advancements, both in imaging as well as treatment delivery, have enabled more precise radiation treatment that has reduced treatment-related 
morbidity and improved patient outcomes. However, even with the use of modern radiation techniques, there are still opportunities for further improvement (4).

The immune system has a critical role in tumor development, and the development of immune evasion by tumors is a key step in carcinogenesis $(6,7)$. Attempts to reinvigorate an anti-tumor immune response have been widely integrated into practice following the development of the immune checkpoint inhibitors (ICIs) targeted against the immune checkpoint receptors cytotoxic T-lymphocyte-associated protein 4 (CTLA-4), programmed cell death protein 1 (PD-1), and programmed death-ligand 1 (PD-L1). Since the initial FDA approval of ipilimumab (a CTLA-4 inhibitor) in 2011 for the treatment of metastatic melanoma based on a proven overall survival advantage (8), antibodies blocking CTLA-4 and PD-1/PD-L1 have been tested and approved across a wide spectrum of malignancies. In HNSCC, both pembrolizumab and nivolumab (PD-1 inhibitors) have gained FDA approval for use in recurrent/metastatic HNSCC after progression through platinum-based chemotherapy (9-11). Pembrolizumab additionally has been approved in the US for use in the first line setting in patients with recurrent/metastatic HNSCC, either in combination with chemotherapy or alone as monotherapy depending on tumor/tumor microenvironment PDL1 expression (12).

Unfortunately, overall response rates to PD-1 inhibitors in unselected patients with HNSCC remain low at approximately $10-20 \%(9-12)$, although patients who do respond can have long-lasting, durable remissions, as has been the case with other solid tumor patients who respond to PD-1 blockade (13). The possibility of durable long-term response has been a driver of the rapid uptake in clinical practice and has invigorated efforts to develop predictive biomarkers. Tumor mutational burden, a potential surrogate for tumor neoantigens that can be recognized by the immune system, is one such biomarker, leading to the first ever histology-agnostic FDA approval of the PD-1 inhibitor pembrolizumab for mismatch repair deficient tumors of any histology $(14,15)$, though there is increasing recognition that the types and functional nature of mutations may be as important as the number of mutations present (16). PD-L1 expression on both tumor cells and infiltrated immune cells has also been explored as a biomarker across several histologies with varying results; in HNSCC, subgroup analyses of Checkmate 141, KEYNOTE-040, and KEYNOTE-048 all suggest that higher PD-L1 expression does correlate with the likelihood of survival benefit (10-12). It is less clear whether patients with low or no PD-L1 expression still benefit from PD-1 directed therapy; analyses of Checkmate 141 and KEYNOTE-048 show questionable benefit for the PD-L1 negative subgroup when comparing the treatment and control arms $(11,17)$. Finally, for HNSCC patients, HPV-associated malignancies with relatively fewer tumor mutations as compared to tobaccoassociated malignancies may also respond to immune checkpoint blockade as novel viral-associated neoantigens might be recognized by the immune system. Indeed, subgroup analyses of the Checkmate 141 and KEYNOTE-040 trials did not show any clear differences in response or clinical benefit based on p16 expression status (a surrogate for HPV-associated tumors) $(10,11)$.

In addition to better patient selection through the use of predictive biomarkers, augmenting the anti-tumor immune response with other therapies could also improve immunotherapy response rates. Radiation therapy increasingly has been recognized to have diverse immunomodulatory effects, and there has consequently been intense interest in possible synergism between radiation therapy and immunotherapy. In this review, we will summarize the preclinical data that illustrate the immune effects of radiation therapy, review the unique immune landscape of HNSCC, and finally discuss both current preclinical and clinical data relevant to the combination of radiation therapy and immunotherapy specifically in HNSCC (Figure 1).

\section{IMMUNE EFFECTS OF RADIATION THERAPY}

Traditionally, the anti-tumor effects of radiation therapy have been attributed to direct cytotoxicity secondary to the induction of DNA damage, and while it was known over 40 years ago that radiation therapy also depends on an intact immune system to exert its full anti-tumor effect (18), the interaction between the immune system and radiation therapy has garnered more interest in the past two decades. It is now recognized that the immune effects of radiation may contribute significantly to an anti-tumor response; however, these immune effects are also quite complex and can be both immunostimulatory and immunosuppressive.

Radiation can induce immunogenic cell death, which gives rise to adaptive immune responses $(19,20)$. Many mechanisms can be involved in this process, and a full detailed review is beyond the scope of this discussion. However, recent studies have shown radiation can promote release of danger-associated molecular patterns such as calreticulin, ATP, and $\operatorname{HMGB}(20,21)$. Radiation also induces release of cytosolic DNA, which triggers the cGAS/STING pathway to upregulate production of type-I interferon $(22,23)$. Type-I interferon is crucial for the activation of dendritic cells, which ultimately recruit and prime T-cells. These signals together are critical for the initial development of an immune response specific to tumor neoantigens.

Radiation can promote anti-tumor immunity through additional mechanisms. Radiation can diversify antigen presentation by tumor cells through promotion of intracellular peptide degradation as well as upregulation of $\mathrm{MHC}$ expression $(24,25)$. This ultimately can enhance recognition and tumor cell killing by cytotoxic T-cells (26). Radiation has also been associated with increased production of other immune stimulating cytokines and chemokines, which together can promote the infiltration of T-cells into tumors and modulate the function of these T-cells, as well as dendritic cells and macrophages (21).

Radiation also has immunosuppressive effects that could be detrimental to an anti-tumor immune response. Lymphocytes 


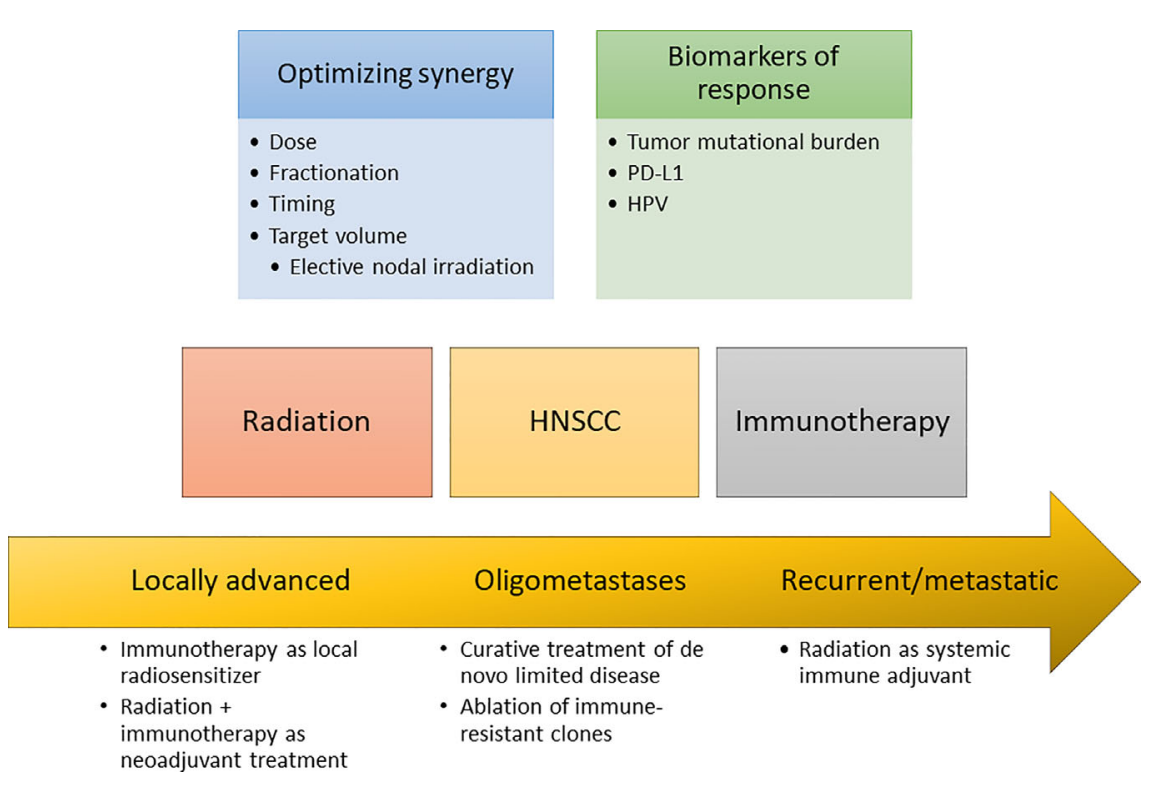

FIGURE 1 | Opportunities for radioimmunotherapy in HNSCC.

are radiosensitive, with in vitro studies demonstrating that $3 \mathrm{~Gy}$ of radiation is enough to deplete $90 \%$ of human lymphocytes (27). This may be overly simplistic, however, as more recent work suggests differential radiosensitivity of T-cell subtypes. Preexisting intra-tumoral $\mathrm{T}$-cells in particular appear to be potentially more radioresistant than either circulating T-cells or lymphoid tissue $\mathrm{T}$-cells. These intra-tumoral $\mathrm{T}$ cells survive even high doses $(20 \mathrm{~Gy})$ of radiation in preclinical studies and can develop a similar transcriptomic profile to tissue-resident memory T-cells, which are also thought to be radioresistant (28, 29). These intra-tumoral T-cells can mediate some of the antitumor immune effects of high dose radiation. Regardless, clinical data suggest that radiation-induced lymphopenia may be a negative prognostic factor in patients treated with PD-1 and CTLA-4 inhibitors (30).

Within the local tumor microenvironment, a variety of inhibitory immune cells, such as T-regulatory cells (Tregs), myeloid-derived suppressor cells (MDSCs), and tumorassociated macrophages (TAMs, and specifically M2 macrophages), are often already present. In several studies, radiation increases recruitment of these inhibitory immune cells and can also modulate their function towards an even more immunosuppressive phenotype (21). There may also be dose-dependent effects of radiation; for instance, VanpouilleBox et al. demonstrated that as radiation doses were escalated to 12-18 Gy, there was induction of Trex1, a DNA exonuclease which degrades cytosolic DNA and thus prevents activation of the cGAS/STING pathway (23). The balance between competing activating and inhibitory immune responses, then, likely plays a key role in the probability of a successful anti-tumor immune response and provides opportunity for therapeutic intervention.

\section{IMMUNE LANDSCAPE OF HNSCC}

Work over the past decade has helped characterize the immune landscape of HNSCC. As noted above, HPV-associated oropharyngeal SCC is a distinct disease entity from other nonHPV-driven, tobacco-associated HNSCC, with a distinct immune profile. Using data from The Cancer Genome Atlas, Mandal et al. showed that HPV-positive tumors were significantly more immune infiltrated than HPV-negative tumors (31). However, both HPV-positive and HPV-negative HNSCC had the highest rate of immunosuppressive Treg infiltration among 10 different cancer types. There was a correlation between the molecular smoking signature of HNSCC tumors and increased tumor mutational burden, but also conversely an inverse association between the molecular smoking signature and immune infiltration, despite this higher tumor mutation burden (and therefore presumably increased neoantigen load). This suggests that tobacco-associated tumors can still be immunologically cold despite their higher mutational load. Further work has demonstrated that HPV-positive tumors are associated with increased T-cell receptor diversity, higher levels of immune cytolytic activity, and an overall enriched inflammatory response $(32,33)$. The anatomic subsite where head and neck cancer develops likely plays a key role in tumor immunity as well; the oropharynx contains particularly lymphoid-rich tissue, and this unique immune environment may explain why the improved prognosis for HPV-driven HNSCC is largely limited to oropharyngeal tumors (34). Additional work on oropharyngeal SCC has confirmed a higher degree of infiltration of CD8+ T-cells in HPV-positive vs HPV-negative tumors (35). Overall, these studies suggest that the increased sensitivity of HPV-associated oropharyngeal SCC to chemotherapy and radiation therapy may 
at least in part be mediated through immune mechanisms $(36,37)$, and that differing immunotherapeutic approaches may be optimal for HPV-positive and HPV-negative HNSCC.

HNSCC also appears to be uniquely associated with high levels of natural killer (NK) cell infiltration, even when compared to other highly-immune infiltrated cancer types $(31,35)$. Patients with high levels of NK cell infiltration were also found to have improved survival compared to those with low levels of infiltration (31). The potential anti-tumor effects of NK cells is an emerging area of research and has been reviewed elsewhere (38); currently, there is limited clinical data on their role in HNSCC, or whether opportunities for synergy between NKdirected therapies and radiation exist.

\section{PRECLINICAL EVIDENCE FOR RADIOIMMUNOTHERAPY IN HNSCC MODELS}

\section{Augmenting Anti-tumor Cellular Immunity}

Preclinical work in HNSCC models has demonstrated synergy between radiation and immunotherapy. In a poorly immunogenic orthotopic HNSCC mouse model, Oweida et al. demonstrated effective tumor cell killing when both $10 \mathrm{~Gy}$ of radiation and an anti PD-L1 antibody were administered together, but not for either treatment individually (39). Tumor control was correlated with increased tumor T-cell infiltration and was abrogated when CD4+ and CD8+ T-cells were depleted. In addition, although much of research on anti-tumor immunity has focused on the role of T-cells, work from Kim et al. in a mouse model of HPVassociated HNSCC suggests that the combination of radiation and PD-1 inhibition also promotes maturation and activation of Bcells, leading to the development of memory B-cells, plasma cells, and antigen-specific B-cells, as well as increasing formation of Bcell germinal centers in tumor draining lymph nodes (40). Finally, there is growing interest in harnessing additional molecular pathways to promote anti-tumor immunity. For instance, in a mouse model of HPV-driven carcinoma, Dillon et al. demonstrated that inhibitors of ATR, a key protein in the DNA damage response pathway, significantly sensitized tumors to radiation, and this effect was correlated with upregulation of interferon-stimulated genes and a significant increase in innate immune cell infiltration into the tumor microenvironment (41). Xiao et al. showed that ASTX600, an inhibitor of IAP1/2 and XIAP, proteins that modulate apoptosis and the tumor necrosis factor signaling pathway, significantly enhanced T-cell mediated tumor cell killing when combined with radiation and PD-1 inhibition in a mouse model of oral cavity carcinoma (42).

\section{Decreasing an Immunosuppressive Microenvironment}

The immunosuppressive microenvironment remains a challenge even with combined radiation and immunotherapy. In a followup study, Oweida et al. demonstrated that the anti-tumor immune responses to combined radiation and PD-1 inhibition in their HNSCC mouse model were ultimately transient, as compensatory mechanisms of immune evasion were activated, including upregulation of another immune checkpoint, TIM-3, as well as increased tumor infiltration of Tregs $(39,43)$. Adding an antiTIM-3 antibody further delayed tumor growth, but the response was still not durable; only targeted depletion of Tregs was able to induce durable immunologic memory. Another group has explored the use of cyclophosphamide and an inhibitor of inducible nitric oxide synthase (iNOS) as immunomodulatory agents in a mouse model of HPV-associated HNSCC. When combined with traditional chemoradiation, addition of these two agents increased the CD8+ T-cell/Treg ratio and decreased immunosuppression (44). In this particular model system the combination of radiation with PD-1 and CTLA- 4 inhibition only minimally altered the immunologically cold tumor microenvironment, but the addition of cyclophosphamide and the iNOS inhibitor shifted the balance of infiltrated immune cells away from immunosuppressive types (such as MDSCs) to those more associated with anti-tumor immunity (such as dendritic cells and anti-tumor M1 macrophages). This led to an increased CD8+ $\mathrm{T}$-cell-dependent response and complete tumor rejection in more than $70 \%$ of the treated mice (45). This is now being investigated in a clinical trial, NCT03844763, which explores the use of cyclophosphamide, avelumab (a PD-L1 inhibitor), and radiation therapy in the treatment of recurrent/metastatic HNSCC.

\section{Radiation Dose and Fractionation Effects}

Additional studies have demonstrated the importance of radiation dose and fractionation in generating an effective antitumor immune response. Consistent with work in other diseases (46), Morisada et al. showed in a syngeneic mouse oral cavity carcinoma model that hypofractionated radiation (16 Gy in two fractions) was associated with preservation of both peripheral and tumor-infiltrating lymphocytes, reduction of both peripheral and tumor-associated MDSCs, and increased expression of interferon genes, when compared to conventionally fractionated radiation (20 Gy in 10 fractions) (47). Moreover, analysis of the draining lymph nodes (which notably were included within the radiation fields) suggested that 20 Gy in 10 fractions suppressed local tumor-specific T-cell responses. Consequently, only 16 Gy in two fractions demonstrated synergy with an anti-PD-1 antibody in these mice. Additional work by this group suggests a dosedependent effect of radiation on both antigen release and T-cell priming, with $8 \mathrm{~Gy}$ in a single fraction enhancing these pathways compared to $2 \mathrm{~Gy}$ in a single fraction, resulting in increased tumor cell susceptibility to T-cell mediated killing (48). However, the doses used in these preclinical models differ from those used in clinical practice, as do the size of the treated tumors, and so it is uncertain how these findings might translate to the treatment of patients.

\section{CLINICAL EVIDENCE FOR RADIOIMMUNOTHERAPY IN HNSCC}

\section{Recurrent/Metastatic Setting}

Despite the widespread use of ICIs in advanced malignancies, prospective clinical data on their combination with radiation 
therapy remain scarce, particularly in HNSCC. The unique immune-related adverse effects (irAEs) that have been observed with ICIs are now well established (49) and there have been concerns that the pro-inflammatory effects of radiation could enhance toxicities when combined with ICIs. Reassuringly, however, most of the available clinical data to date suggests that the combination of radiation and ICIs is generally well tolerated (50). For instance, in a cohort of 133 patients with metastatic melanoma, non-small cell lung cancer (NSCLC), or renal cell cancer who received palliative radiation to a wide range of anatomic sites, Bang et al. demonstrated numerically higher rates of irAEs when radiation was given within 14 days of immunotherapy, but the toxicities were generally mild with rates of grade $3+$ toxicity less than $10 \%$ (51). Similarly, a prospective phase I trial of pembrolizumab and stereotactic body radiotherapy (SBRT) in patients with a variety of metastatic solid tumors also demonstrated a grade $3+$ toxicity rate of less than $10 \%$ (52). Notably, this study did include four patients with HNSCC, and radiation was delivered to two distinct anatomic sites in more than $60 \%$ of the cohort. Finally, a phase 2 trial which randomized 62 patients with metastatic HNSCC to nivolumab with or without SBRT to a single metastatic site did not find a significant difference in either grade 3-5 adverse events (13\% for nivolumab alone $v s 10 \%$ for nivolumab with SBRT, $\mathrm{p}=0.70)$ or any grade adverse events (70\% for nivolumab alone $v s 87 \%$ for nivolumab with SBRT, $\mathrm{p}=$ 0.12 ) with the addition of SBRT (53).

Nevertheless, a few key issues must be considered when interpreting these and other safety data. Just as dose and fractionation likely affect potential anti-tumor immunity induced by radiation (as demonstrated in preclinical work), it is probable that these parameters influence potential toxicities when combined with ICIs. The relative timing of radiation and immunotherapy is likely to be important as well; notably, radiation recall, a relatively rare, unpredictable, and poorly understood phenomenon wherein an inflammatory reaction can develop in previously irradiated tissue following administration of a new systemic agent (54), has now been reported following ICI administration (55, 56). Additionally, the anatomic site treated with radiation could influence the side effect profile of combination treatment; for instance, the landmark PACIFIC trial, which demonstrated a significant overall survival benefit to adjuvant durvalumab (an anti-PD-L1 antibody) after definitive chemoradiation for stage III NSCLC, also showed an increase in any-grade pneumonitis with the addition of durvalumab (although rates of clinically relevant pneumonitis, i.e. grade $3+$, were similar between treatment groups and low overall) (57). Within the brain, there is a potential increased risk of developing radiation necrosis after treatment of brain metastases with combined ICIs and radiation $(58,59)$. Finally, as discussed earlier, in certain settings radiation can induce lymphopenia, which could ultimately interfere with the efficacy of ICIs (30). These data highlight the importance of collecting robust radiation treatment and toxicity data to facilitate future analyses as we study combination radiation and immunotherapy treatments.
There are very few efficacy data relevant to the addition of radiation to ICIs in patients with recurrent or metastatic HNSCC. In general, the primary rationale for radiation in this setting is to help stimulate a systemic anti-tumor immune response, or abscopal effect. This is particularly difficult to study retrospectively, as disentangling a true abscopal effect from a delayed response to immunotherapy is challenging (60). The only available prospective data for HNSCC comes from the randomized phase 2 trial noted above, in which 62 patients with metastatic HNSCC were randomized to nivolumab with or without SBRT to a single metastatic site $(9$ Gy $\times 3$ fractions, between the first and second doses of nivolumab). Ultimately, there was no improvement in overall response rate $(34.5 \%$ for nivolumab alone $v s$ 29.0\% for nivolumab with SBRT, $\mathrm{p}=0.86$ ) (53). In NSCLC, a similarly designed phase 2 trial of pembrolizumab with or without SBRT to a single metastatic site in patients with advanced NSCLC also failed to meet its primary endpoint, although it did demonstrate a doubling of overall response rate with the addition of SBRT that was not statistically significant (18\% for pembrolizumab alone vs 36\% for pembrolizumab with SBRT, $\mathrm{p}=0.07)(61)$. Differences between the designs of these two studies include the anti-PD-1 agent used (nivolumab vs pembrolizumab), the type of cancer (HNSCC $v s$ NSCLC), timing of SBRT (between first and second dose of nivolumab $v s$ prior to starting pembrolizumab), and dose of SBRT $(9$ Gy $\times 3$ fractions $v s 8$ Gy $\times 3$ fractions). Given the results of these trials, further research is clearly needed; Table 1 summarizes ongoing trials that will help address these questions specifically in patients with recurrent/metastatic HNSCC. Notably, however, only a few of these studies are randomized, and so any efficacy data will require confirmation in larger, phase 3 trials.

Finally, as noted above, there is growing recognition of an oligometastatic disease state. Contrary to previous conceptualization of metastatic disease as inevitably widespread and thus incurable, the oligometastatic hypothesis suggests that there is a wide range of metastatic potential that varies among different cancers and from patient to patient, and that an intermediate state likely exists between purely localized disease and widely metastatic disease, wherein a limited number of metastases might develop with limited further metastatic potential (62). Aggressive local treatment of patients with limited metastases would thus potentially offer a significant survival benefit. Results from several randomized phase 2 trials have supported this hypothesis (though notably HNSCC was not represented in any of these studies) (63-67). Consequently, there is interest in the addition of ICIs to radiation in this population of patients to improve outcomes (68). In this setting, radiation would be administered at ablative doses to all metastatic sites, and so the addition of ICIs would also be intended to augment the local effects of radiation at each treatment site. To our knowledge, no prospective clinical data has yet been published on the combination of radiation and ICIs in patients with oligometastatic HNSCC, though there is at least one ongoing clinical trial (NCT03283605, which examines the use of durvalumab, tremelimumab [a CTLA-4 inhibitor], and SBRT in patients with HNSCC with fewer than 10 metastases). 
TABLE 1 | Ongoing trials evaluating combinations of ICls and radiation in the management of recurrent/metastatic HNSCC.

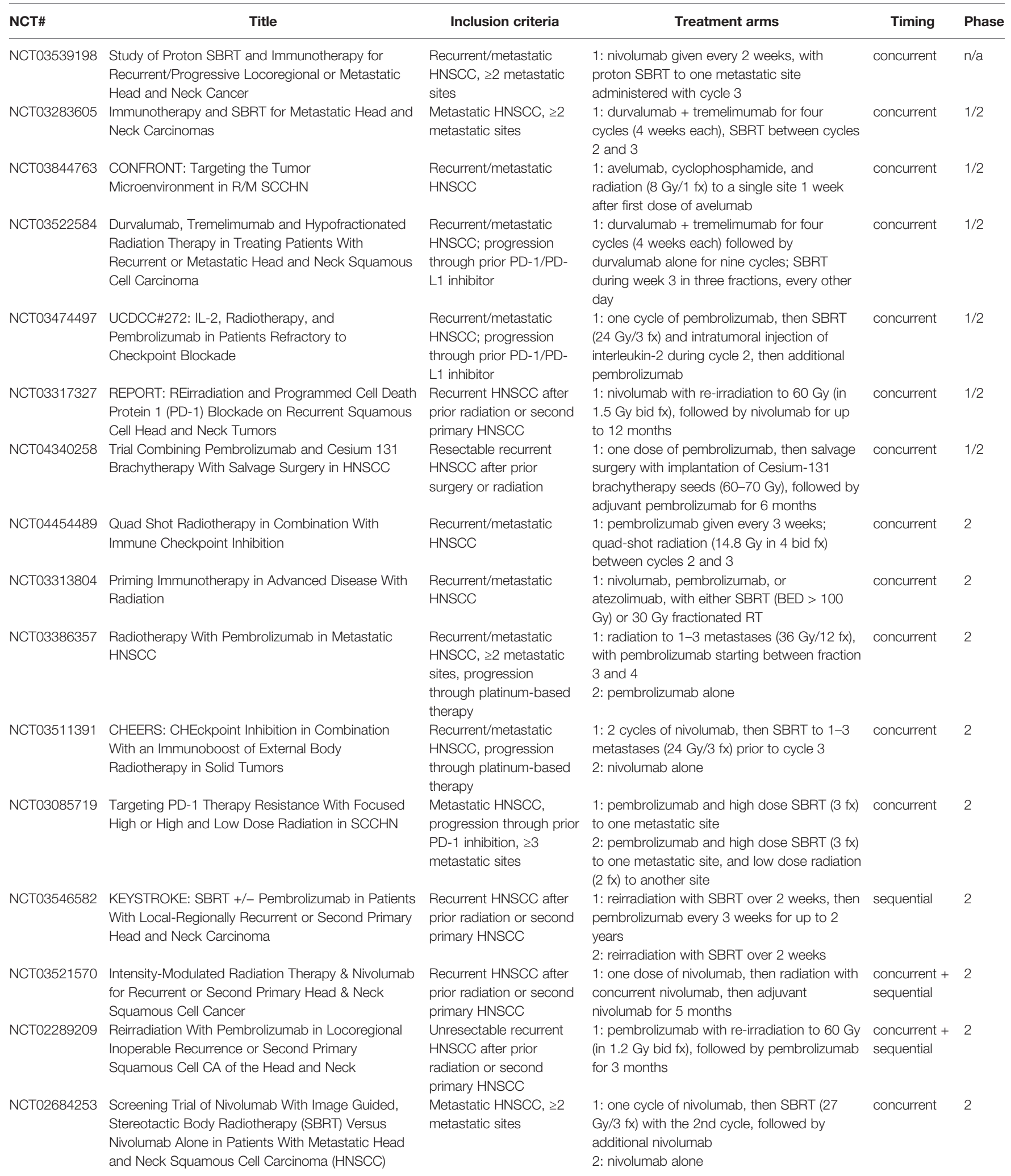

BED, biologically effective dose; bid, twice a day; fx, fraction; HNSCC, head and neck squamous cell carcinoma; ICls, immune checkpoint inhibitors; SBRT, stereotactic body radiotherapy. 
Related to the overall concept of oligometastases is oligoprogression, or the development of a limited number of progressive metastatic lesions after a period of stability on systemic therapy (69). In the context of ICIs, oligoprogression may herald general immune escape in patients who had previously been responding to treatment. However, in certain cases oligoprogression may develop as the result of resistant tumor clones that lack particular tumor antigens or antigen presentation, or because of differences in the underlying immune microenvironment of the anatomic site that permit localized immune escape (e.g. brain) $(70,71)$. If this is the case, local treatment such as radiation to these oligoprogressive sites may enable the patient to continue to derive benefit from ICIs (72-74). This paradigm is being tested prospectively in SCCHN (NCT03085719).

\section{Locally Advanced/Definitive Setting}

ICIs are being investigated in the setting of curative treatment of earlier stages of disease across all cancer types, including HNSCC. Addition of ICIs to radiation in this setting would be intended to potentially augment the local effects of radiation (i.e. as a radiosensitizer) and address micrometastatic disease. Several possible combinations are under investigation-immunotherapy added to a chemoradiation regimen to intensify therapy (for patients with currently poor outcomes), immunotherapy given concurrently with radiation instead of chemotherapy or with a lower dose of radiation (potentially as a way to reduce treatment morbidity while maintaining overall efficacy), or immunotherapy administered adjuvantly and/or as induction (i.e. sequential therapy). To date adjuvant immunotherapy has proven successful in NSCLC; as noted earlier, the PACIFIC trial demonstrated a significant and meaningful overall survival benefit for adjuvant durvalumab starting within 6 weeks of completing standard chemoradiation for unresectable stage III NSCLC, with an increase in 2-year overall survival from 55.6 to $66.3 \%$ (75). Of note, the magnitude of benefit was greater patients who were randomized within 2 weeks of completing chemoradiation. Adjuvant immunotherapy also has newly demonstrated success in esophagogastric cancer; Checkmate577 demonstrated improved disease-free survival with the administration of adjuvant nivolumab following neoadjuvant chemoradiation and surgical resection in patients with esophageal and gastroesophageal cancer, though full trial results have yet to be presented (76).

As shown in Table 2, ongoing trials are evaluating various combinations of radiation and ICIs for HNSCC in the definitive setting, and several have now reported safety data. In general, combinations of PD-1/PD-L1 inhibitors with definitive radiation appear well tolerated with no unexpected toxicities. KEYCHAIN is a randomized phase 2 study of radiation combined with concurrent and adjuvant pembrolizumab compared with radiation and concurrent cisplatin in intermediate-risk p16positive HNSCC; the safety lead-in phase of the study found only one dose-limiting toxicity (grade 4 adrenal insufficiency) among eight patients in the pembrolizumab arm, and so the trial has proceeded to its phase 2 component (77). A single arm phase
2 trial of radiation administered with concurrent and adjuvant pembrolizumab in cisplatin-ineligible patients with locally advanced HNSCC similarly demonstrated relatively low toxicity in the first 12 enrolled patients, and 11 of 12 patients received all planned cycles of pembrolizumab (78). Finally, PembroRad is a randomized phase 2 trial of radiation combined with concurrent pembrolizumab versus radiation combined with concurrent cetuximab, again in cisplatin-ineligible patients with locally advanced HNSCC. There have been 133 patients randomized in a 1:1 fashion, and the pembrolizumab arm was found to have significantly less mucositis or dermatitis within the radiation field than the cetuximab arm (79).

Early results also suggest that intensification of existing chemoradiation regimens with the addition of ICIs is reasonably safe. In a small phase 1 trial of concurrent and adjuvant avelumab added to standard cetuximab/radiation in 10 cisplatin-ineligible patients with locally advanced HNSCC, no grade 4-5 toxicities were observed, and only one of eight evaluable patients discontinued avelumab for toxicity (80). $\mathrm{REACH}$ is a phase 3 trial that is also comparing concurrent avelumab, cetuximab, and radiation, followed by 12 months of adjuvant avelumab, against either standard bolus cisplatin with radiation or cetuximab with radiation (depending on if the patient is judged to be fit for cisplatin or not) in patients with locally advanced HNSCC; results for the 82 patients randomized during the safety phase of the trial suggested that addition of avelumab was tolerable, with $88 \%$ of patients completing concurrent avelumab as per protocol, and rates of grade 4+ events similar between control and experimental arms (81). Similarly, a single arm phase $1 \mathrm{~b}$ study of the addition of concurrent and adjuvant pembrolizumab to standard radiation and weekly cisplatin in patients with locally advanced HNSCC demonstrated in 59 patients that concurrent pembrolizumab did not prevent patients from completing chemoradiation, and only 5 of 59 patients ultimately discontinued treatment because of irAEs (82). Finally, RTOG 3504 is a four-arm phase 1 trial in patients with intermediate or high risk HNSCC that is examining the addition of concurrent and adjuvant nivolumab to either radiation alone or radiation with weekly cisplatin, bolus cisplatin, or cetuximab; safety results from the latter three arms again demonstrated that nivolumab did not prevent timely completion of chemoradiation, and rates of dose-limiting toxicities were low (83).

Efficacy data, however, have not yet been reported from most of these or other ongoing trials. One of the single arm phase 2 trials noted above (78) of radiation with concurrent and adjuvant pembrolizumab in cisplatin-ineligible patients with locally advanced HNSCC ultimately enrolled 29 patients, and reported 1 -yr progression-free survival and overall survival of 76 and $86 \%$, respectively (84). Notably, the phase 3 Javelin 100 study is a double-blind, placebo-controlled trial that randomized 697 patients with locally advanced HNSCC to standard of care cisplatin-based chemoradiation with or without concurrent and adjuvant (for 12 months) avelumab, with progression-free survival as the primary endpoint. Unfortunately, this trial was recently terminated for likely futility after a preplanned interim 
TABLE 2 | Ongoing trials evaluating combinations of ICls and radiation in the definitive management of locally advanced HNSCC.

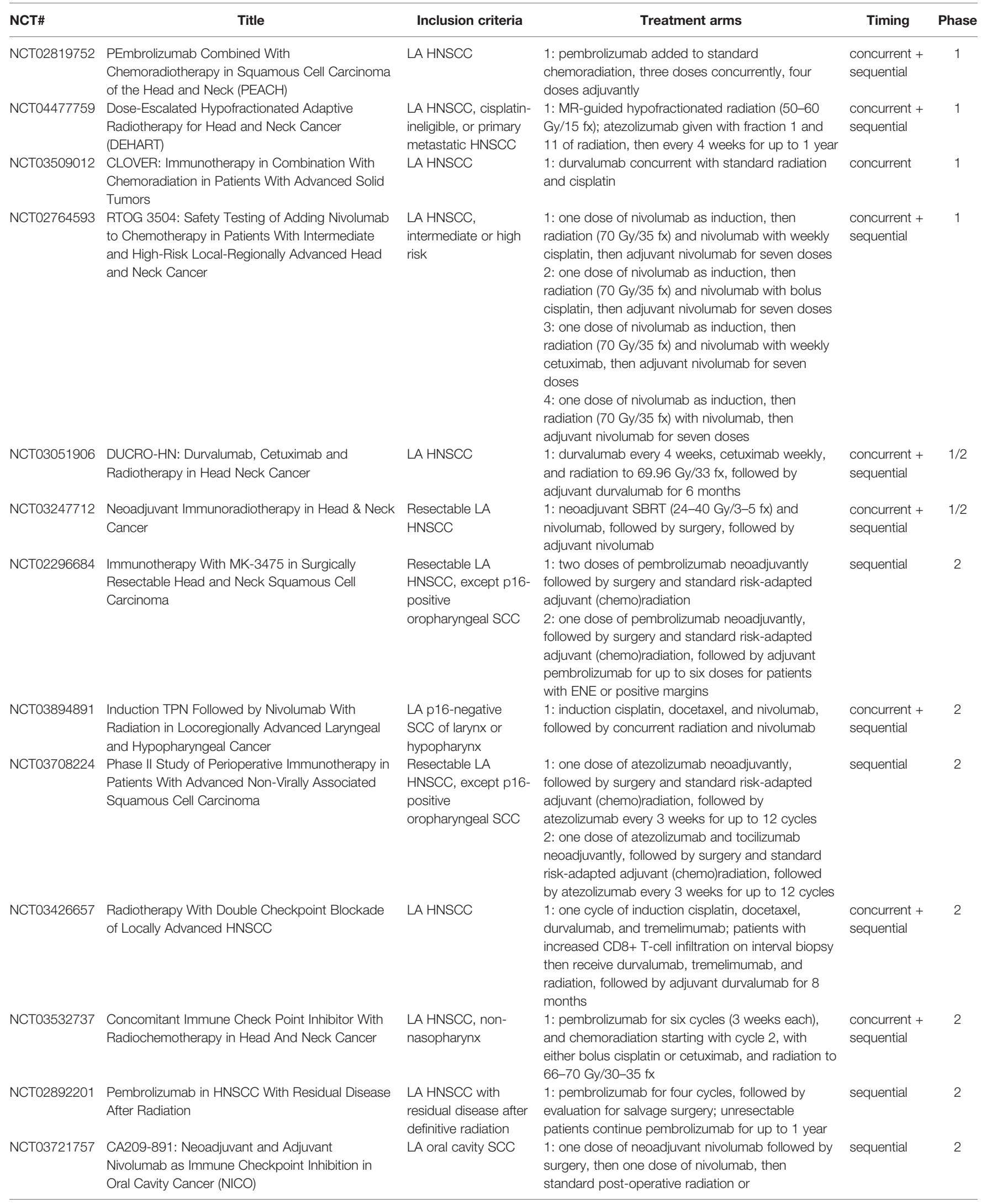


TABLE 2 | Continued

\begin{tabular}{|c|c|c|c|c|c|}
\hline NCT\# & Title & Inclusion criteria & Treatment arms & Timing & Phase \\
\hline & & & $\begin{array}{l}\text { chemoradiation ( } 60 \mathrm{~Gy} / 30 \mathrm{fx} \text { ), then } 6 \text { months of } \\
\text { adjuvant nivolumab }\end{array}$ & & \\
\hline NCT03944915 & $\begin{array}{l}\text { De-Escalation Therapy for Human Papillomavirus } \\
\text { Negative Disease (DEPEND) }\end{array}$ & $\begin{array}{l}\text { LA p16-negative } \\
\text { HNSCC }\end{array}$ & $\begin{array}{l}\text { 1: induction carboplatin, paclitaxel, and nivolumab, } \\
\text { followed by response-adapted chemoradiation } \\
\text { (66-75 Gy) }\end{array}$ & sequential & 2 \\
\hline NCT04405154 & $\begin{array}{l}\text { A Study of Concomitant Camrelizumab With } \\
\text { Chemoradiation for Locally Advanced Head and } \\
\text { Neck Cancer }\end{array}$ & LA HNSCC & $\begin{array}{l}\text { 1: camrelizumab for eight cycles ( } 2 \text { weeks each), } \\
\text { with standard chemoradiation (bolus cisplatin and } \\
\text { radiation [ } 66 \mathrm{~Gy} / 33 \mathrm{fx}] \text { ) starting with cycle } 2\end{array}$ & $\begin{array}{l}\text { concurrent + } \\
\text { sequential }\end{array}$ & 2 \\
\hline \multirow[t]{2}{*}{ NCT02777385 } & \multirow[t]{2}{*}{$\begin{array}{l}\text { Pembrolizumab in Combination With Cisplatin and } \\
\text { Intensity Modulated Radiotherapy (IMRT) in Head } \\
\text { and Neck Cancer }\end{array}$} & \multirow[t]{2}{*}{$\begin{array}{l}\text { LA HNSCC, } \\
\text { intermediate or high } \\
\text { risk }\end{array}$} & $\begin{array}{l}\text { 1: pembrolizumab for one initial dose, then } \\
\text { concurrent with radiation and weekly cisplatin, then } \\
\text { adjuvant pembrolizumab for a total of eight doses }\end{array}$ & $\begin{array}{l}\text { concurrent }+ \\
\text { sequential }\end{array}$ & \multirow[t]{2}{*}{2} \\
\hline & & & $\begin{array}{l}\text { 2: radiation and weekly cisplatin, followed by } \\
\text { adjuvant pembrolizumab for eight doses }\end{array}$ & sequential & \\
\hline NCT03383094 & $\begin{array}{l}\text { KEYCHAIN: Chemoradiation vs Immunotherapy } \\
\text { and Radiation for Head and Neck Cancer }\end{array}$ & $\begin{array}{l}\text { LA HNSCC, p16- } \\
\text { positive, intermediate } \\
\text { risk }\end{array}$ & $\begin{array}{l}\text { 1: pembrolizumab and standard radiation to } 70 \\
\text { Gy/33-35 fx, followed by adjuvant pembrolizumab } \\
\text { for up to } 20 \text { cycles ( } 3 \text { weeks each) }\end{array}$ & concurrent & 2 \\
\hline & & & $\begin{array}{l}\text { 2: standard chemoradiation to } 70 \mathrm{~Gy} / 33-35 \mathrm{fx} \text { with } \\
\text { bolus cisplatin }\end{array}$ & & \\
\hline NCT02707588 & $\begin{array}{l}\text { PembroRad: Tolerance and Efficacy of } \\
\text { Pembrolizumab or Cetuximab Combined With RT } \\
\text { in Patients With Locally Advanced HNSCC }\end{array}$ & LA HNSCC & $\begin{array}{l}\text { 1: radiation ( } 69.96 \mathrm{~Gy} / 33 \mathrm{fx}) \text { with concurrent } \\
\text { pembrolizumab } \\
\text { 2: radiation }(69.96 \mathrm{~Gy} / 33 \mathrm{fx}) \text { with concurrent } \\
\text { cetuximab }\end{array}$ & concurrent & 2 \\
\hline NCT02609503 & $\begin{array}{l}\text { Pembrolizumab + Radiation for Locally Adv SCC } \\
\text { of the Head and Neck (SCCHN) Not Eligible } \\
\text { Cisplatin }\end{array}$ & $\begin{array}{l}\text { LA HNSCC, cisplatin- } \\
\text { ineligible }\end{array}$ & $\begin{array}{l}\text { 1: radiation ( } 70 \mathrm{~Gy} / 35 \mathrm{fx} \text { ) with three concurrent } \\
\text { cycles of pembrolizumab, then three adjuvant } \\
\text { cycles }\end{array}$ & $\begin{array}{l}\text { concurrent + } \\
\text { sequential }\end{array}$ & 2 \\
\hline NCT03258554 & $\begin{array}{l}\text { NRG-HN004: Radiation Therapy With Durvalumab } \\
\text { or Cetuximab in Treating Patients With } \\
\text { Locoregionally Advanced Head and Neck Cancer } \\
\text { Who Cannot Take Cisplatin }\end{array}$ & $\begin{array}{l}\text { LA HNSCC, cisplatin- } \\
\text { ineligible }\end{array}$ & $\begin{array}{l}\text { 1: durvalumab for seven cycles ( } 4 \text { weeks each); } \\
\text { radiation to } 70 \text { Gy/35 fx starting week } 2 \\
\text { 2: cetuximab for eight cycles (weekly); radiation to } \\
70 \text { Gy/35 fx starting week } 2\end{array}$ & $\begin{array}{l}\text { concurrent + } \\
\text { sequential }\end{array}$ & $2 / 3$ \\
\hline NCT01810913 & $\begin{array}{l}\text { RTOG 1216: Testing Docetaxel-Cetuximab or the } \\
\text { Addition of an Immunotherapy Drug, } \\
\text { Atezolizumab, to the Usual Chemotherapy and } \\
\text { Radiation Therapy in High-Risk Head and Neck } \\
\text { Cancer }\end{array}$ & $\begin{array}{l}\text { Resected LA } \\
\text { HNSCC, except p16- } \\
\text { positive } \\
\text { oropharyngeal SCC, } \\
\text { with pathologic ENE } \\
\text { or positive margins }\end{array}$ & $\begin{array}{l}\text { 1: atezolizumab for eight cycles ( } 3 \text { weeks each) } \\
\text { following surgery, with standard chemoradiation (to } \\
60 \text { Gy/30 fx with weekly cisplatin) starting week } 2\end{array}$ & $\begin{array}{l}\text { concurrent + } \\
\text { sequential }\end{array}$ & $2 / 3$ \\
\hline NCT03811015 & $\begin{array}{l}\text { EA3161: Testing Immunotherapy Versus } \\
\text { Observation in Patients With HPV Throat Cancer }\end{array}$ & $\begin{array}{l}\text { p16-positive } \\
\text { oropharyngeal SCC, } \\
\text { intermediate risk }\end{array}$ & $\begin{array}{l}\text { 1: radiation (70 Gy/35 fx) and concurrent weekly } \\
\text { cisplatin, then adjuvant nivolumab for } 12 \text { months } \\
\text { 2: radiation ( } 70 \mathrm{~Gy} / 35 \mathrm{fx} \text { ) and concurrent weekly } \\
\text { cisplatin, then observation }\end{array}$ & sequential & $2 / 3$ \\
\hline NCT03452137 & $\begin{array}{l}\text { IMvoke010: A Study of Atezolizumab (Anti-Pd-L1 } \\
\text { Antibody) as Adjuvant Therapy After Definitive } \\
\text { Local Therapy in Patients With High-Risk Locally } \\
\text { Advanced Squamous Cell Carcinoma of the Head } \\
\text { and Neck }\end{array}$ & $\begin{array}{l}\text { LA HNSCC after } \\
\text { definitive local } \\
\text { therapy } \\
\text { (chemoradiation or } \\
\text { surgery + [chemo] } \\
\text { radiation) }\end{array}$ & $\begin{array}{l}\text { 1: adjuvant atezolizumab for } 1 \text { year } \\
\text { 2: placebo for } 1 \text { year }\end{array}$ & sequential & 3 \\
\hline NCT03576417 & $\begin{array}{l}\text { NIVOPOSTOP: A Trial Evaluating the Addition of } \\
\text { Nivolumab to Cisplatin-RT for Treatment of } \\
\text { Cancers of the Head and Neck }\end{array}$ & $\begin{array}{l}\text { Resected LA } \\
\text { HNSCC, with ENE, } \\
\text { positive margins, or } \\
\text { multiple positive } \\
\text { nodes }\end{array}$ & $\begin{array}{l}\text { 1: one dose of nivolumab, then nivolumab } \\
\text { concurrent with radiation ( } 66 \mathrm{~Gy} / 33 \mathrm{fx} \text { ) and bolus } \\
\text { cisplatin } \\
\text { 2: radiation ( } 66 \mathrm{~Gy} / 33 \mathrm{fx} \text { ) with bolus cisplatin }\end{array}$ & $\begin{array}{l}\text { concurrent + } \\
\text { sequential }\end{array}$ & 3 \\
\hline NCT03673735 & $\begin{array}{l}\text { Maintenance Immune Check-point Inhibitor } \\
\text { Following Post-operative Chemo-radiation in } \\
\text { Subjects With HPV-negative HNSCC (ADHERE) }\end{array}$ & $\begin{array}{l}\text { Surgically resected } \\
\text { p16-negative HNSCC } \\
\text { with pathologic ENE } \\
\text { or positive margins }\end{array}$ & $\begin{array}{l}\text { 1: one dose of induction durvalumab followed by } \\
\text { standard chemoradiation (bolus cisplatin and } \\
\text { radiation [ } 66 \text { Gy/33 fx]), followed by } 6 \text { months of } \\
\text { adjuvant durvalumab } \\
\text { 2: standard chemoradiation (bolus cisplatin and } \\
\text { radiation [ } 66 \mathrm{~Gy} / 33 \mathrm{fx}] \text { ) }\end{array}$ & sequential & 3 \\
\hline NCT03700905 & $\begin{array}{l}\text { IMSTAR-HN: Study of Nivolumab Alone or in } \\
\text { Combination With Ipilimumab as Immunotherapy } \\
\text { vs Standard Follow-up in Surgical Resectable } \\
\text { HNSCC After Adjuvant Therapy }\end{array}$ & $\begin{array}{l}\text { Resectable LA } \\
\text { HNSCC, except p16- } \\
\text { positive } \\
\text { oropharyngeal SCC }\end{array}$ & $\begin{array}{l}\text { 1: one dose of neoadjuvant nivolumab followed by } \\
\text { surgery, followed by standard risk adapted } \\
\text { adjuvant (chemo)radiation, followed by either } \\
\text { adjuvant nivolumab or adjuvant nivolumab+ } \\
\text { ipilimumab for } 6 \text { months } \\
\text { 2: surgical resection followed by standard risk } \\
\text { adapted adjuvant (chemo)radiation }\end{array}$ & sequential & 3 \\
\hline
\end{tabular}


TABLE 2 | Continued

\begin{tabular}{|c|c|c|c|c|c|}
\hline NCT\# & Title & Inclusion criteria & Treatment arms & Timing & Phase \\
\hline NCT03765918 & $\begin{array}{l}\text { Study of Pembrolizumab Given Prior to Surgery } \\
\text { and in Combination With Radiotherapy Given } \\
\text { Post-surgery for Advanced Head and Neck } \\
\text { Squamous Cell Carcinoma (MK-3475-689) }\end{array}$ & $\begin{array}{l}\text { Resectable LA } \\
\text { HNSCC }\end{array}$ & $\begin{array}{l}\text { 1: two doses of neoadjuvant pembrolizumab, then } \\
\text { surgery, then pembrolizumab with adjuvant } \\
\text { radiation or chemoradiation, then adjuvant } \\
\text { pembrolizumab for } 12 \text { additional doses } \\
\text { 2: surgery followed by adjuvant radiation or } \\
\text { chemoradiation }\end{array}$ & $\begin{array}{l}\text { concurrent + } \\
\text { sequential }\end{array}$ & 3 \\
\hline NCT03673735 & $\begin{array}{l}\text { ADHERE: Maintenance Immune Check-point } \\
\text { Inhibitor Following Post-operative Chemo- } \\
\text { radiation in Subjects With HPV-negative HNSCC }\end{array}$ & $\begin{array}{l}\text { Resected LA } \\
\text { HNSCC, except p16- } \\
\text { positive } \\
\text { oropharyngeal SCC, } \\
\text { with pathologic ENE } \\
\text { or positive margins }\end{array}$ & $\begin{array}{l}\text { 1: following surgery, one dose of durvalumab, then } \\
\text { standard radiation ( } 66 \mathrm{~Gy} / 33 \mathrm{fx} \text { ) with bolus } \\
\text { cisplatin, then adjuvant durvalumab for six doses } \\
\text { 2: following surgery, standard radiation ( } 66 \mathrm{~Gy} / 33 \\
\mathrm{fx} \text { ) with bolus cisplatin }\end{array}$ & sequential & 3 \\
\hline NCT03040999 & $\begin{array}{l}\text { KEYNOTE-412: Study of Pembrolizumab (MK- } \\
\text { 3475) or Placebo With Chemoradiation in } \\
\text { Participants With Locally Advanced Head and } \\
\text { Neck Squamous Cell Carcinoma }\end{array}$ & LA HNSCC & $\begin{array}{l}\text { 1: one dose of induction pembrolizumab, then } \\
\text { pembrolizumab with radiation ( } 70 \mathrm{~Gy} / 35 \mathrm{fx} \text { ) and } \\
\text { bolus cisplatin, then adjuvant pembrolizumab for a } \\
\text { total of } 17 \text { doses } \\
\text { 2: standard radiation ( } 70 \mathrm{~Gy} / 35 \mathrm{fx} \text { ) with bolus } \\
\text { cisplatin }\end{array}$ & $\begin{array}{l}\text { concurrent + } \\
\text { sequential }\end{array}$ & 3 \\
\hline NCT02999087 & $\begin{array}{l}\text { REACH: Randomized Trial of Avelumab- } \\
\text { cetuximab-radiotherapy Versus SOCs in LA } \\
\text { SCCHN }\end{array}$ & $\begin{array}{l}\text { LA HNSCC, both } \\
\text { cisplatin eligible and } \\
\text { ineligible }\end{array}$ & $\begin{array}{l}\text { 1: cetuximab and avelumab, one dose prior to } \\
\text { radiation, then concurrent during radiation ( } 69.96 \\
\text { Gy/33 fx), then adjuvant avelumab for } 12 \text { months } \\
\text { 2: standard radiation ( } 69.96 \mathrm{~Gy} / 33 \mathrm{fx} \text { ) with } \\
\text { concurrent bolus cisplatin for cisplatin-eligible } \\
\text { patients } \\
\text { 3: standard radiation ( } 69.96 \mathrm{~Gy} / 33 \mathrm{fx} \text { ) with } \\
\text { concurrent cetuximab for cisplatin-ineligible } \\
\text { patients }\end{array}$ & $\begin{array}{l}\text { concurrent + } \\
\text { sequential }\end{array}$ & 3 \\
\hline NCT02952586 & $\begin{array}{l}\text { Javelin 100: Study To Compare Avelumab In } \\
\text { Combination With Standard of Care } \\
\text { Chemoradiotherapy (SoC CRT) Versus SoC CRT } \\
\text { for Definitive Treatment In Patients With Locally } \\
\text { Advanced Squamous Cell Carcinoma Of The } \\
\text { Head And Neck }\end{array}$ & LA HNSCC & $\begin{array}{l}\text { 1: one dose of induction avelumab, then avelumab } \\
\text { with radiation ( } 70 \mathrm{~Gy} / 35 \mathrm{fx} \text { ) and bolus cisplatin, } \\
\text { then adjuvant avelumab for } 12 \text { months } \\
\text { 2: radiation ( } 70 \mathrm{~Gy} / 35 \mathrm{fx} \text { ) and bolus cisplatin }\end{array}$ & $\begin{array}{l}\text { concurrent + } \\
\text { sequential }\end{array}$ & 3 \\
\hline
\end{tabular}

ENE, extranodal extension; fx, fraction; HNSCC, head and neck squamous cell carcinoma; ICIs, immune checkpoint inhibitors; LA, locally advanced; SBRT, stereotactic body radiotherapy.

analysis performed by their independent data monitoring committee (85).

Possible reasons for the failure of Javelin 100 to achieve its primary endpoint may be revealed when more complete data are available. However, in the interim, it is interesting to highlight distinctions from the successful incorporation of PD-L1 blockade into the treatment of locally advanced NSCLC as evidenced by the PACIFIC study. A predominant mode of failure in locally advanced HNSCC is locoregional recurrence (4), whereas distant metastases are more common in locally advanced NSCLC (86). Thus, examining patterns of failure in the Javelin 100 study and comparing these to patterns of failure in the PACIFIC study may inform whether ICIs in this setting are mainly eradicating systemic micrometastatic disease versus also improving local disease control. Unfortunately, PACIFIC did not collect data distinguishing intrathoracic failures within versus outside of the radiation field, highlighting the importance of thorough radiation data collection to tease out these types of questions (87). Given the high risk of lymph node metastases in patients with locally advanced HNSCC, standard radiation generally entails elective treatment of the draining cervical lymph node chains (in contrast to NSCLC, where elective lymph nodes are not intentionally irradiated). These draining lymph nodes are precisely where antigen-presenting cells migrate to for
T-cell priming, following radiation to the primary tumor $(21,25)$. Correlative positron emission tomography-computed tomography (PET-CT) studies from a recently published clinical trial of neoadjuvant ICIs (nivolumab or nivolumab and ipilimumab) prior to surgery in patients with oral cavity SCC provides further support for the importance of the draining lymph nodes; following initiation of neoadjuvant ICIs, there was a high rate of increased fluorodeoxyglucose (FDG) uptake in the draining cervical lymph nodes on an interval PET-CT, which ultimately on surgical pathology demonstrated only reactive findings without any evidence of cancer. This observed increase in FDG uptake may therefore represent radiographic evidence of a mounting immune response (88). Given the radiosensitivity of lymphocytes, then, it seems possible that radiation (particularly longer conventionally fractionated regimens) that electively treats the draining lymph nodes following the receipt of ICI could actually hinder T-cell priming. Indeed, as noted above, there is some preclinical data to support this, as Morisada et al. demonstrated in an syngeneic mouse model of oral cavity cancer that $20 \mathrm{~Gy}$ in 10 fractions compared to $16 \mathrm{~Gy}$ in 2 fractions to both the primary tumor and the draining lymph nodes blunted tumor-specific CD8+ T-cell responses within those draining lymph nodes (although notably tumors were implanted in the mice legs and thus this is not a perfect model for head and neck lymphatics) (47). The phase 2 trial 
reported by Weiss et al. also noted a rate of grade $3+$ lymphopenia of $58.6 \%$ (84). Another notable issue is that the design of Javelin 100 , as well as many of the other trials described above, incorporated both concurrent and adjuvant ICIs in the experimental arm, whereas PACIFIC (and Checkmate-577) only tested the value of adjuvant immunotherapy. Timing and sequencing of ICIs and radiation remains a critical issue that requires further study, although the concerns regarding radiation-induced $\mathrm{T}$-cell death may be particularly problematic when ICI is administered concurrently as compared with sequentially (89). Finally, as demonstrated in the preclinical work above, radiation dose and fractionation are also likely critical to successful synergy between radiation and ICIs; however, the hypofractionated regimens that appear to have the greatest immunologic potential in preclinical models differ tremendously from the long conventionally fractionated regimens (1.8-2 Gy/fraction) used in the current standard management of HNSCC. PACIFIC did also employ conventional fractionation, though standard total doses for NSCLC are somewhat lower than for HNSCC (54-66 Gy versus 70 Gy). Overall, given the years of experience supporting the current standard radiation regimen and fields used in the definitive management of HNSCC, careful studies will be required to determine what kinds of modifications to elective nodal irradiation, timing/sequencing, dose, and/or fractionation are required to maximize synergy with ICIs and ultimately improve patient outcomes. There is already significant heterogeneity amongst the ongoing trials in Tables $\mathbf{1}$ and $\mathbf{2}$ with regard to these parameters, and so examining the results collectively will hopefully be informative.

\section{REFERENCES}

1. Bray F, Ferlay J, Soerjomataram I, Siegel RL, Torre LA, Jemal A. Global cancer statistics 2018: GLOBOCAN estimates of incidence and mortality worldwide for 36 cancers in 185 countries. CA Cancer J Clin (2018) 68:394-424. doi: $10.3322 /$ caac. 21492

2. Taberna M, Mena M, Pavón MA, Alemany L, Gillison ML, Mesía R. Human papillomavirus-related oropharyngeal cancer. Ann Oncol (2017) 28:2386-98. doi: 10.1093/annonc/mdx304

3. Coutard H. Principles Of X Ray Therapy Of Malignant Diseases. Lancet (1934) 224:1-8. doi: 10.1016/S0140-6736(00)90085-0

4. Leeman JE, Li J-G, Pei X, Venigalla P, Zumsteg ZS, Katsoulakis E, et al. Patterns of Treatment Failure and Postrecurrence Outcomes Among Patients With Locally Advanced Head and Neck Squamous Cell Carcinoma After Chemoradiotherapy Using Modern Radiation Techniques. JAMA Oncol (2017) 3:1487-94. doi: 10.1001/jamaoncol.2017.0973

5. Vengaloor Thomas T, Packianathan S, Bhanat E, Albert A, Abraham A, Gordy X, et al. Oligometastatic head and neck cancer: Comprehensive review. Head Neck (2020) 42:2194-201. doi: 10.1002/hed.26144

6. Mascaux C, Angelova M, Vasaturo A, Beane J, Hijazi K, Anthoine G, et al. Immune evasion before tumour invasion in early lung squamous carcinogenesis. Nature (2019) 571:570-5. doi: 10.1038/s41586-019-1330-0

7. Galon J, Bruni D. Tumor Immunology and Tumor Evolution: Intertwined Histories. Immunity (2020) 52:55-81. doi: 10.1016/j.immuni.2019.12.018

8. Hodi FS, O’Day SJ, McDermott DF, Weber RW, Sosman JA, Haanen JB, et al. Improved survival with ipilimumab in patients with metastatic melanoma. N Engl J Med (2010) 363:711-23. doi: 10.1056/NEJMoa1003466

9. Seiwert TY, Burtness B, Mehra R, Weiss J, Berger R, Eder JP, et al. Safety and clinical activity of pembrolizumab for treatment of recurrent or metastatic

\section{CONCLUSIONS/FUTURE DIRECTIONS}

There remains excitement for the possibility of combining radiation therapy and immunotherapy to improve outcomes for patients with HNSCC. Ongoing trials will help advance this emerging field, and the developing paradigm of oligometastatic disease provides further opportunity to integrate improving systemic and local therapies. Biomarker studies conducted in parallel will also inform optimal patient selection for combined treatment approaches. Moreover, while this review has largely focused on ICIs (and PD-1/PD-L1 targeted therapies in particular) given their widespread use, immunotherapeutic agents targeting other checkpoints and pathways are in development as well (90), as are trials testing their combination with radiation (e.g. NCT04220775). Nevertheless, significant work remains to be done in both the preclinical and clinical space to determine the dose, fractionation, timing, target, and field size of radiation that will be the most synergistic with immunotherapies. Finding the optimal balance between the immunostimulatory and immunosuppressive effects of radiation is key and hopefully will herald continued improvement in outcomes for patients with HNSCC.

\section{AUTHOR CONTRIBUTIONS}

JQ: conceptualization; writing, original draft; writing, review and editing. JS: conceptualization; writing, review and editing. All authors contributed to the article and approved the submitted version.

squamous cell carcinoma of the head and neck (KEYNOTE-012): an openlabel, multicentre, phase 1b trial. Lancet Oncol (2016) 17:956-65. doi: 10.1016/S1470-2045(16)30066-3

10. Cohen EEW, Soulières D, Le Tourneau C, Dinis J, Licitra L, Ahn M-J, et al. Pembrolizumab versus methotrexate, docetaxel, or cetuximab for recurrent or metastatic head-and-neck squamous cell carcinoma (KEYNOTE-040): a randomised, open-label, phase 3 study. Lancet (2019) 393:156-67. doi: 10.1016/S0140-6736(18)31999-8

11. Ferris RL, Blumenschein G, Fayette J, Guigay J, Colevas AD, Licitra L, et al. Nivolumab for Recurrent Squamous-Cell Carcinoma of the Head and Neck. N Engl J Med (2016) 375:1856-67. doi: 10.1056/NEJMoa1602252

12. Burtness B, Harrington KJ, Greil R, Soulières D, Tahara M, de Castro G, et al. Pembrolizumab alone or with chemotherapy versus cetuximab with chemotherapy for recurrent or metastatic squamous cell carcinoma of the head and neck (KEYNOTE-048): a randomised, open-label, phase 3 study. Lancet (2019) 394:1915-28. doi: 10.1016/S0140-6736(19)32591-7

13. Alexander BM, Schoenfeld JD, Trippa L. Hazards of Hazard Ratios Deviations from Model Assumptions in Immunotherapy. $N$ Engl J Med (2018) 378:1158-9. doi: 10.1056/NEJMc1716612

14. Le DT, Uram JN, Wang H, Bartlett BR, Kemberling H, Eyring AD, et al. PD-1 Blockade in Tumors with Mismatch-Repair Deficiency. N Engl J Med (2015) 372:2509-20. doi: 10.1056/NEJMoa1500596

15. Marabelle A, Fakih MG, Lopez J, Shah M, Shapira-Frommer R, Nakagawa K, et al. $1192 \mathrm{O}$ - Association of tumour mutational burden with outcomes in patients with select advanced solid tumours treated with pembrolizumab in KEYNOTE-158. Ann Oncol (2019) 30:v477-8. doi: 10.1093/annonc/ $\mathrm{mdz} 253.018$

16. Chen DS, Mellman I. Elements of cancer immunity and the cancer-immune set point. Nature (2017) 541:321-30. doi: 10.1038/nature21349 
17. Schoenfeld JD, Fell G, Haddad RI, Trippa L. Keynote 48: Is it really for everyone? Oral Oncol (2020) 105:104762. doi: 10.1016/j.oraloncology.2020. 104762

18. Stone HB, Peters LJ, Milas L. Effect of host immune capability on radiocurability and subsequent transplantability of a murine fibrosarcoma. J Natl Cancer Inst (1979) 63:1229-35. doi: 10.1093/jnci/63.5.1229

19. Galluzzi L, Vitale I, Warren S, Adjemian S, Agostinis P, Martinez AB, et al. Consensus guidelines for the definition, detection and interpretation of immunogenic cell death. J Immunother Cancer (2020) 8:e000337. doi: 10.1136/jitc-2019-000337

20. Golden EB, Frances D, Pellicciotta I, Demaria S, Helen Barcellos-Hoff M, Formenti SC. Radiation fosters dose-dependent and chemotherapy-induced immunogenic cell death. Oncoimmunology (2014) 3:e28518. doi: 10.4161/ onci.28518

21. Weichselbaum RR, Liang H, Deng L, Fu Y-X. Radiotherapy and immunotherapy: a beneficial liaison? Nat Rev Clin Oncol (2017) 14:365-79. doi: 10.1038/nrclinonc.2016.211

22. Deng L, Liang H, Xu M, Yang X, Burnette B, Arina A, et al. STING-Dependent Cytosolic DNA Sensing Promotes Radiation-Induced Type I InterferonDependent Antitumor Immunity in Immunogenic Tumors. Immunity (2014) 41:843-52. doi: 10.1016/j.immuni.2014.10.019

23. Vanpouille-Box C, Alard A, Aryankalayil MJ, Sarfraz Y, Diamond JM, Schneider RJ, et al. DNA exonuclease Trex1 regulates radiotherapy-induced tumour immunogenicity. Nat Commun (2017) 8:15618. doi: 10.1038/ ncomms 15618

24. Reits EA, Hodge JW, Herberts CA, Groothuis TA, Chakraborty M, Wansley EK, et al. Radiation modulates the peptide repertoire, enhances MHC class I expression, and induces successful antitumor immunotherapy. J Exp Med (2006) 203:1259-71. doi: 10.1084/jem.20052494

25. Sharabi AB, Nirschl CJ, Kochel CM, Nirschl TR, Francica BJ, Velarde E, et al. Stereotactic Radiation Therapy Augments Antigen-Specific PD-1-Mediated Antitumor Immune Responses via Cross-Presentation of Tumor Antigen. Cancer Immunol Res (2015) 3:345-55. doi: 10.1158/2326-6066.CIR-14-0196

26. Garnett CT, Palena C, Chakraborty M, Chakarborty M, Tsang K-Y, Schlom J, et al. Sublethal irradiation of human tumor cells modulates phenotype resulting in enhanced killing by cytotoxic T lymphocytes. Cancer Res (2004) 64:7985-94. doi: 10.1158/0008-5472.CAN-04-1525

27. Nakamura N, Kusunoki Y, Akiyama M. Radiosensitivity of CD4 or CD8 positive human T-lymphocytes by an in vitro colony formation assay. Radiat Res (1990) 123:224-7. doi: 10.2307/3577549

28. Arina A, Beckett M, Fernandez C, Zheng W, Pitroda S, Chmura SJ, et al. Tumor-reprogrammed resident $\mathrm{T}$ cells resist radiation to control tumors. Nat Commun (2019) 10:3959. doi: 10.1038/s41467-019-11906-2

29. Grayson JM, Harrington LE, Lanier JG, Wherry EJ, Ahmed R. Differential sensitivity of naive and memory CD8+ T cells to apoptosis in vivo. J Immunol Baltim Md 1950 (2002) 169:3760-70. doi: 10.4049/jimmunol.169.7.3760

30. Pike LRG, Bang A, Mahal BA, Taylor A, Krishnan M, Spektor A, et al. The Impact of Radiation Therapy on Lymphocyte Count and Survival in Metastatic Cancer Patients Receiving PD-1 Immune Checkpoint Inhibitors. Int J Radiat Oncol Biol Phys (2019) 103:142-51. doi: 10.1016/j.ijrobp.2018. 09.010

31. Mandal R, Şenbabaoğlu Y, Desrichard A, Havel JJ, Dalin MG, Riaz N, et al. The head and neck cancer immune landscape and its immunotherapeutic implications. JCI Insight (2016) 1:e89829. doi: 10.1172/jci.insight.89829

32. Wang J, Sun H, Zeng Q, Guo X-J, Wang H, Liu H-H, et al. HPV-positive status associated with inflamed immune microenvironment and improved response to anti-PD-1 therapy in head and neck squamous cell carcinoma. Sci Rep (2019) 9:13404. doi: 10.1038/s41598-019-49771-0

33. Chen Y-P, Wang Y-Q, Lv J-W, Li Y-Q, Chua MLK, Le Q-T, et al. Identification and validation of novel microenvironment-based immune molecular subgroups of head and neck squamous cell carcinoma: implications for immunotherapy. Ann Oncol (2019) 30:68-75. doi: 10.1093/ annonc/mdy 470

34. Chakravarthy A, Henderson S, Thirdborough SM, Ottensmeier CH, Su X, Lechner $\mathrm{M}$, et al. Human Papillomavirus Drives Tumor Development Throughout the Head and Neck: Improved Prognosis Is Associated With an Immune Response Largely Restricted to the Oropharynx. J Clin Oncol (2016) 34:4132-41. doi: 10.1200/JCO.2016.68.2955
35. Schoenfeld JD, Gjini E, Rodig SJ, Tishler RB, Rawal B, Catalano PJ, et al. Evaluating the PD-1 Axis and Immune Effector Cell Infiltration in Oropharyngeal Squamous Cell Carcinoma. Int J Radiat Oncol Biol Phys (2018) 102:137-45. doi: 10.1016/j.ijrobp.2018.05.002

36. Spanos WC, Nowicki P, Lee DW, Hoover A, Hostager B, Gupta A, et al. Immune response during therapy with cisplatin or radiation for human papillomavirus-related head and neck cancer. Arch Otolaryngol Head Neck Surg (2009) 135:1137-46. doi: 10.1001/archoto.2009.159

37. Özcan-Wahlbrink M, Schifflers C, Riemer AB. Enhanced Radiation Sensitivity of Human Papillomavirus-Driven Head and Neck Cancer: Focus on Immunological Aspects. Front Immunol (2019) 10:2831. doi: 10.3389/ fimmu.2019.02831

38. Shimasaki N, Jain A, Campana D. NK cells for cancer immunotherapy. Nat Rev Drug Discovery (2020) 19:200-18. doi: 10.1038/s41573-019-0052-1

39. Oweida A, Lennon S, Calame D, Korpela S, Bhatia S, Sharma J, et al. Ionizing radiation sensitizes tumors to PD-L1 immune checkpoint blockade in orthotopic murine head and neck squamous cell carcinoma. Oncoimmunology (2017) 6:e1356153. doi: 10.1080/2162402X.2017.1356153

40. Kim SS, Shen S, Miyauchi S, Sanders PD, Franiak-Pietryga I, Mell L, et al. Sharabi AB. B Cells Improve Overall Survival in HPV-Associated Squamous Cell Carcinomas and Are Activated by Radiation and PD-1 Blockade. Clin Cancer Res (2020) 26:3345-59. doi: 10.1158/1078-0432.CCR-19-3211

41. Dillon MT, Bergerhoff KF, Pedersen M, Whittock H, Crespo-Rodriguez E, Patin EC, et al. ATR Inhibition Potentiates the Radiation-induced Inflammatory Tumor Microenvironment. Clin Cancer Res (2019) 25:3392403. doi: 10.1158/1078-0432.CCR-18-1821

42. Xiao R, Allen CT, Tran L, Patel P, Park S-J, Chen Z, et al. Antagonist of cIAP1/ 2 and XIAP enhances anti-tumor immunity when combined with radiation and PD-1 blockade in a syngeneic model of head and neck cancer. Oncoimmunology (2018) 7:e1471440. doi: 10.1080/2162402X.2018.1471440

43. Oweida A, Hararah MK, Phan A, Binder D, Bhatia S, Lennon S, et al. Resistance to Radiotherapy and PD-L1 Blockade Is Mediated by TIM-3 Upregulation and Regulatory T-Cell Infiltration. Clin Cancer Res (2018) 24:5368-80. doi: 10.1158/1078-0432.CCR-18-1038

44. Hanoteau A, Newton JM, Krupar R, Huang C, Liu H-C, Gaspero A, et al. Tumor microenvironment modulation enhances immunologic benefit of chemoradiotherapy. J Immunother Cancer (2019) 7:10. doi: 10.1186/s40425018-0485-9

45. Newton JM, Hanoteau A, Liu H-C, Gaspero A, Parikh F, Gartrell-Corrado $\mathrm{RD}$, et al. Immune microenvironment modulation unmasks therapeutic benefit of radiotherapy and checkpoint inhibition. I Immunother Cancer (2019) 7:216. doi: 10.1186/s40425-019-0698-6

46. Dewan MZ, Galloway AE, Kawashima N, Dewyngaert JK, Babb JS, Formenti SC, et al. Fractionated but not single-dose radiotherapy induces an immunemediated abscopal effect when combined with anti-CTLA-4 antibody. Clin Cancer Res (2009) 15:5379-88. doi: 10.1158/1078-0432.CCR-09-0265

47. Morisada M, Clavijo PE, Moore E, Sun L, Chamberlin M, Van Waes C, et al. PD-1 blockade reverses adaptive immune resistance induced by high-dose hypofractionated but not low-dose daily fractionated radiation. Oncoimmunology (2018) 7:e1395996. doi: 10.1080/2162402X.2017.1395996

48. Morisada M, Moore EC, Hodge R, Friedman J, Cash HA, Hodge JW, et al. Dose-dependent enhancement of T-lymphocyte priming and CTL lysis following ionizing radiation in an engineered model of oral cancer. Oral Oncol (2017) 71:87-94. doi: 10.1016/j.oraloncology.2017.06.005

49. Martins F, Sofiya L, Sykiotis GP, Lamine F, Maillard M, Fraga M, et al. Adverse effects of immune-checkpoint inhibitors: epidemiology, management and surveillance. Nat Rev Clin Oncol (2019) 16:563-80. doi: 10.1038/s41571019-0218-0

50. Hwang WL, Pike LRG, Royce TJ, Mahal BA, Loeffler JS. Safety of combining radiotherapy with immune-checkpoint inhibition. Nat Rev Clin Oncol (2018) 15:477-94. doi: 10.1038/s41571-018-0046-7

51. Bang A, Wilhite TJ, Pike LRG, Cagney DN, Aizer AA, Taylor A, et al. Multicenter Evaluation of the Tolerability of Combined Treatment With PD-1 and CTLA-4 Immune Checkpoint Inhibitors and Palliative Radiation Therapy. Int J Radiat Oncol Biol Phys (2017) 98:344-51. doi: 10.1016/ j.ijrobp.2017.02.003

52. Luke JJ, Lemons JM, Karrison TG, Pitroda SP, Melotek JM, Zha Y, et al. Safety and Clinical Activity of Pembrolizumab and Multisite Stereotactic Body 
Radiotherapy in Patients With Advanced Solid Tumors. J Clin Oncol (2018) 36:1611-8. doi: 10.1200/JCO.2017.76.2229

53. McBride S, Sherman E, Tsai CJ, Baxi S, Aghalar J, Eng J, et al. Randomized Phase II Trial of Nivolumab With Stereotactic Body Radiotherapy Versus Nivolumab Alone in Metastatic Head and Neck Squamous Cell Carcinoma. J Clin Oncol (2020) 39(1):30-7. doi: 10.1200/JCO.20.00290

54. Azria D, Magné N, Zouhair A, Castadot P, Culine S, Ychou M, et al. Radiation recall: a well recognized but neglected phenomenon. Cancer Treat Rev (2005) 31:555-70. doi: 10.1016/j.ctrv.2005.07.008

55. Shibaki R, Akamatsu H, Fujimoto M, Koh Y, Yamamoto N. Nivolumab induced radiation recall pneumonitis after two years of radiotherapy. Ann Oncol (2017) 28:1404-5. doi: 10.1093/annonc/mdx115

56. Schoenfeld JD, Nishino M, Severgnini M, Manos M, Mak RH, Hodi FS. Pneumonitis resulting from radiation and immune checkpoint blockade illustrates characteristic clinical, radiologic and circulating biomarker features. J Immunother Cancer (2019) 7:112. doi: 10.1186/s40425-019-0583-3

57. Antonia SJ, Villegas A, Daniel D, Vicente D, Murakami S, Hui R, et al. Durvalumab after Chemoradiotherapy in Stage III Non-Small-Cell Lung Cancer. N Engl J Med (2017) 377:1919-29. doi: 10.1056/NEJMoa1709937

58. Colaco RJ, Martin P, Kluger HM, Yu JB, Chiang VL. Does immunotherapy increase the rate of radiation necrosis after radiosurgical treatment of brain metastases? J Neurosurg (2016) 125:17-23. doi: 10.3171/2015.6.JNS142763

59. Martin AM, Cagney DN, Catalano PJ, Alexander BM, Redig AJ, Schoenfeld JD, et al. Immunotherapy and Symptomatic Radiation Necrosis in Patients With Brain Metastases Treated With Stereotactic Radiation. JAMA Oncol (2018) 4:1123-4. doi: 10.1001/jamaoncol.2017.3993

60. Reynders K, Illidge T, Siva S, Chang JY, De Ruysscher D. The abscopal effect of local radiotherapy: using immunotherapy to make a rare event clinically relevant. Cancer Treat Rev (2015) 41:503-10. doi: 10.1016/j.ctrv.2015.03.011

61. Theelen WSME, Peulen HMU, Lalezari F, van der Noort V, de Vries JF, Aerts JGJV, et al. Effect of Pembrolizumab After Stereotactic Body Radiotherapy vs Pembrolizumab Alone on Tumor Response in Patients With Advanced NonSmall Cell Lung Cancer: Results of the PEMBRO-RT Phase 2 Randomized Clinical Trial. JAMA Oncol (2019) 5(9):1276-82. doi: 10.1001/jamaoncol. 2019.1478

62. Hellman S, Weichselbaum RR. Oligometastases. J Clin Oncol (1995) 13:8-10. doi: 10.1200/JCO.1995.13.1.8

63. Palma DA, Olson R, Harrow S, Gaede S, Louie AV, Haasbeek C, et al. Stereotactic ablative radiotherapy versus standard of care palliative treatment in patients with oligometastatic cancers (SABR-COMET): a randomised, phase 2, open-label trial. Lancet Lond Engl (2019) 393:2051-8. doi: 10.1016/ S0140-6736(18)32487-5

64. Gomez DR, Blumenschein GR, Lee JJ, Hernandez M, Ye R, Camidge DR, et al. Local consolidative therapy versus maintenance therapy or observation for patients with oligometastatic non-small-cell lung cancer without progression after first-line systemic therapy: a multicentre, randomised, controlled, phase 2 study. Lancet Oncol (2016) 17:1672-82. doi: 10.1016/S1470-2045(16)30532-0

65. Iyengar P, Wardak Z, Gerber DE, Tumati V, Ahn C, Hughes RS, et al. Consolidative Radiotherapy for Limited Metastatic Non-Small-Cell Lung Cancer: A Phase 2 Randomized Clinical Trial. JAMA Oncol (2018) 4: e173501. doi: 10.1001/jamaoncol.2017.3501

66. Ost P, Reynders D, Decaestecker K, Fonteyne V, Lumen N, De Bruycker A, et al. Surveillance or Metastasis-Directed Therapy for Oligometastatic Prostate Cancer Recurrence: A Prospective, Randomized, Multicenter Phase II Trial. J Clin Oncol (2018) 36:446-53. doi: 10.1200/JCO.2017.75.4853

67. Phillips R, Shi WY, Deek M, Radwan N, Lim SJ, Antonarakis ES, et al. Outcomes of Observation vs Stereotactic Ablative Radiation for Oligometastatic Prostate Cancer: The ORIOLE Phase 2 Randomized Clinical Trial. JAMA Oncol (2020) 6(5):650-9. doi: 10.1001/jamaoncol. 2020.0147

68. Pitroda SP, Chmura SJ, Weichselbaum RR. Integration of radiotherapy and immunotherapy for treatment of oligometastases. Lancet Oncol (2019) 20: e434-42. doi: 10.1016/S1470-2045(19)30157-3

69. Guckenberger M, Lievens Y, Bouma AB, Collette L, Dekker A, deSouza NM, et al. Characterisation and classification of oligometastatic disease: a European Society for Radiotherapy and Oncology and European Organisation for Research and Treatment of Cancer consensus recommendation. Lancet Oncol (2020) 21:e18-28. doi: 10.1016/S1470-2045(19)30718-1
70. Pike LRG, Bang A, Ott P, Balboni T, Taylor A, Catalano P, et al. Radiation and PD-1 inhibition: Favorable outcomes after brain-directed radiation. Radiother Oncol (2017) 124:98-103. doi: 10.1016/j.radonc.2017.06.006

71. Schoenfeld JD. We Are All Connected: Modeling the Tumor-Immune Ecosystem. Trends Cancer (2018) 4:655-7. doi: 10.1016/j.trecan.2018.08.006

72. Bang A, Schoenfeld JD. Immunotherapy and radiotherapy for metastatic cancers. Ann Palliat Med (2019) 8:312-25. doi: 10.21037/apm.2018.07.10

73. Klemen ND, Wang M, Feingold PL, Cooper K, Pavri SN, Han D, et al. Patterns of failure after immunotherapy with checkpoint inhibitors predict durable progression-free survival after local therapy for metastatic melanoma. J Immunother Cancer (2019) 7:196. doi: 10.1186/s40425-019-0672-3

74. Basler L, Kroeze SGC, Guckenberger M. SBRT for oligoprogressive oncogene addicted NSCLC. Lung Cancer Amst Neth (2017) 106:50-7. doi: 10.1016/ j.lungcan.2017.02.007

75. Antonia SJ, Villegas A, Daniel D, Vicente D, Murakami S, Hui R, et al. Overall Survival with Durvalumab after Chemoradiotherapy in Stage III NSCLC. $N$ Engl J Med (2018) 379:2342-50. doi: 10.1056/NEJMoa1809697

76. CheckMate -577, a Phase 3 Trial Evaluating Opdivo (nivolumab) as Adjuvant Therapy for Patients with Resected Esophageal or Gastroesophageal Junction Cancer, Meets Primary Endpoint of Disease-Free Survival. Available at: https:// news.bms.com/news/details/2020/CheckMate-577-a-Phase-3-TrialEvaluating-Opdivo-nivolumab-as-Adjuvant-Therapy-for-Patients-withResected-Esophageal-or-Gastroesophageal-Junction-Cancer-Meets-PrimaryEndpoint-of-Disease-Free-Survival/default.aspx (Accessed September 15, 2020).

77. Sacco AG, Sharabi A, Jing Z, Pittman E, Gold KA, Sumner W, et al. Radiotherapy with Concurrent and Adjuvant Pembrolizumab in Patients with P16-Positive Locoregionally Advanced Head and Neck Cancer: KEYCHAIN Trial Lead-In Results. Int J Radiat Oncol (2019) 105:E363-4. doi: 10.1016/j.jijrobp.2019.06.1701

78. Weiss J, Bauman JR, Deal AM, Sheth S, Chera BS, Shen C, et al. Preliminary toxicity data from the combination of pembrolizumab and definitive-dose radiotherapy for locally advanced head and neck cancer with contraindication to cisplatin therapy. J Clin Oncol (2018) 36:6069-9. doi: 10.1200/ JCO.2018.36.15_suppl.6069

79. Sun XS, Sire C, Tao Y, Martin L, Alfonsi M, Prevost JB, et al. A phase II randomized trial of pembrolizumab versus cetuximab, concomitant with radiotherapy (RT) in locally advanced (LA) squamous cell carcinoma of the head and neck (SCCHN): First results of the GORTEC 2015-01 "PembroRad" trial. J Clin Oncol (2018) 36:6018-8. doi: 10.1200/JCO.2018.36.15_suppl.6018

80. Elbers JBW, Al-Mamgani A, Tesseslaar MET, van den Brekel MWM, Lange $\mathrm{CAH}$, van der Wal JE, et al. Immuno-radiotherapy with cetuximab and avelumab for advanced stage head and neck squamous cell carcinoma: Results from a phase-I trial. Radiother Oncol (2020) 142:79-84. doi: 10.1016/ j.radonc.2019.08.007

81. Tao Y, Auperin A, Sun XS, Sire C, Martin L, Bera G, et al. Avelumabcetuximab-radiotherapy (RT) versus standards of care (SoC) in locally advanced squamous cell carcinoma of the head and neck (SCCHN): Safety phase of the randomized trial GORTEC 2017-01 (REACH). J Clin Oncol (2018) 36:6076-6. doi: 10.1200/JCO.2018.36.15_suppl.6076

82. Powell SF, Gold KA, Gitau MM, Sumey CJ, Lohr MM, McGraw SC, et al. Safety and Efficacy of Pembrolizumab With Chemoradiotherapy in Locally Advanced Head and Neck Squamous Cell Carcinoma: A Phase IB Study. J Clin Oncol (2020) 38:2427-37. doi: 10.1200/JCO.19.03156

83. Ferris RL, Gillison ML, Harris J, Colevas AD, Mell LK, Kong C, et al. Safety evaluation of nivolumab (Nivo) concomitant with cetuximab-radiotherapy for intermediate (IR) and high-risk (HR) local-regionally advanced head and neck squamous cell carcinoma (HNSCC): RTOG 3504. J Clin Oncol (2018) 36:6010-0. doi: 10.1200/JCO.2018.36.15_suppl.6010

84. Weiss J, Vincent B, Deal A, Grilley-Olson J, Patel S, Hackman T, et al. Progression-free survival, overall survival and immunophenotyping outcomes for patients with stage III-IV head and neck cancer and cisplatin contraindication treated with definitive radiotherapy plus pembrolizumab. Int J Radiat Oncol Biol Phys (2020) 106:1221. doi: 10.1016/j.ijrobp.2020.02.003

85. EMD Serono and Pfizer Provide Update on Phase III JAVELIN Head and Neck 100 Study | Pfizer. Available at: https://www.pfizer.com/news/press-release/ press-release-detail/emd_serono_and_pfizer_provide_update_on_phase_iii_ javelin_head_and_neck_100_study (Accessed August 14, 2020). 
86. Bradley JD, Paulus R, Komaki R, Masters G, Blumenschein G, Schild S, et al. Standard-dose versus high-dose conformal radiotherapy with concurrent and consolidation carboplatin plus paclitaxel with or without cetuximab for patients with stage IIIA or IIIB non-small-cell lung cancer (RTOG 0617): a randomised, two-by-two factorial phase 3 study. Lancet Oncol (2015) 16:18799. doi: 10.1016/S1470-2045(14)71207-0

87. Raben D, Rimner A, Senan S, Broadhurst H, Pellas T, Dennis PA, et al. Patterns of Disease Progression with Durvalumab in Stage III Non-small Cell Lung Cancer (PACIFIC). Int J Radiat Oncol Biol Phys (2019) 105:683. doi: 10.1016/j.ijrobp.2019.08.034

88. Schoenfeld JD, Hanna GJ, Jo VY, Rawal B, Chen Y-H, Catalano PS, et al. Neoadjuvant Nivolumab or Nivolumab Plus Ipilimumab in Untreated Oral Cavity Squamous Cell Carcinoma: A Phase 2 Open-Label Randomized Clinical Trial. JAMA Oncol (2020) 6(10):1563-70. doi: 10.1001/jamaoncol. 2020.2955

89. Buchwald ZS, Wynne J, Nasti TH, Zhu S, Mourad WF, Yan W, et al. Radiation, Immune Checkpoint Blockade and the Abscopal Effect: A Critical Review on Timing, Dose and Fractionation. Front Oncol (2018) 8:612. doi: $10.3389 /$ fonc. 2018.00612
90. Marin-Acevedo JA, Dholaria B, Soyano AE, Knutson KL, Chumsri S, Lou Y. Next generation of immune checkpoint therapy in cancer: new developments and challenges. J Hematol OncolJ Hematol Oncol (2018) 11:39. doi: 10.1186/ s13045-018-0582-8

Conflict of Interest: JS reports consulting and scientific advisory board fees from Immunitas, Debiopharm, BMS, Nanobiotix, Tilos, AstraZeneca, LEK, Catenion, ACI Clinical, as well as research funding from Merck, BMS, and Regeneron.

The remaining author declares that the research was conducted in the absence of any commercial or financial relationships that could be construed as a potential conflict of interest.

Copyright (C) 2021 Qian and Schoenfeld. This is an open-access article distributed under the terms of the Creative Commons Attribution License (CC BY). The use, distribution or reproduction in other forums is permitted, provided the original author(s) and the copyright owner(s) are credited and that the original publication in this journal is cited, in accordance with accepted academic practice. No use, distribution or reproduction is permitted which does not comply with these terms. 